\title{
RELATO DE EXPERIÊNCIA: OFICINA PEDAGÓGICA COMO OBJETO DE APRENDIZAGEM NA FORMAÇÃO INICIAL DO PEDAGOGO NO CONSÓRCIO CEDERJ
}

\section{EXPERIENCE REPORT: PEDAGOGICAL WORKSHOP AS AN OBJECT OF LEARNING IN THE INITIAL FORMATION OF THE EDUCATOR IN 'CONSÓRCIO CEDERJ'}

\author{
Silvia Alicia Martínez \\ Universidade Estadual do Norte Fluminense Darcy Ribeiro \\ silvia-martinez@hotmail.com \\ Fabrícia Vieira de Araújo \\ Universidade do Estado do Rio de Janeiro \\ fabricia_va@hotmail.com \\ Suelen Ribeiro de Souza \\ Universidade Estadual do Norte Fluminense Darcy Ribeiro \\ suelenrs_16@hotmail.com \\ Evandro Francisco Marques Vargas \\ Universidade Estadual do Norte Fluminense Darcy Ribeiro \\ evandropeixxe@yahoo.com.br \\ Leandro Garcia Pinho \\ Universidade Estadual do Norte Fluminense Darcy Ribeiro \\ leandrogarciapinho@gmail.com
}

\begin{abstract}
RESUMO: O presente trabalho objetiva abordar, analisar e discutir uma significativa experiência de ensino e aprendizagem adquirida em uma oficina pedagógica, no âmbito do Curso de Pedagogia da Universidade Estadual do Norte Fluminense (UENF), no bojo do Centro de Educação a Distância do Estado do Rio de Janeiro (CEDERJ). Tal atividade foi concretizada por professores, tutores e alunos das disciplinas História na Educação 1 e História na Educação 2 do curso supracitado. A partir das referências de diferentes pesquisadores do campo do Ensino de História e da Educação, discorremos em um momento inicial acerca da organização e estruturação da Oficina, para posteriormente tratarmos da concretização da atividade em si pelos estudantes. A Oficina muito contribuiu para a reflexão acerca das práticas pedagógicas e para uma maior aproximação entre docentes, tutores e estudantes, bem como oportunizou pensamentos acerca das diferentes tecnologias e outros materiais que podem ser empregadas no ensino de História.
\end{abstract}

PALAVRAS-CHAVE: oficina pedagógica; ensino de História; educação a distância; curso de Pedagogia.

ABSTRACT: The present work aims at addressing, analyzing and discussing a significant experience of teaching and learning acquired in a pedagogical workshop, within the course of pedagogy of the State University of the North Fluminense (UENF), in the Centre of 
Distance Education of the State of Rio de Janeiro (CEDERJ). Such activity was accomplished by teachers, tutors and students of the disciplines History in Education 1 and History in Education 2 of the aforementioned course. From the references of different researchers of the field of History Teaching and Education, we have come at an initial moment about the organization and structuring of the workshop, to subsequently embrace the realization of the activity itself by the students. The workshop contributed greatly to reflect on pedagogical practices and for a closer approximation among teachers, tutors and students, as well as it allowed to think the different technologies and other materials that can be employed in the History teaching.

KEYWORDS: Pedagogical workshop; History teaching; distance education; Pedagogy course.

\section{Introdução}

Este artigo coloca em discussão uma experiência realizada pelos autores em quatro polos de apoio presencial de um curso semipresencial de Pedagogia de Educação a Distância. A experiência foi realizada sob a forma de oficinas pedagógicas ocorridas em duas disciplinas metodológicas para o ensino de História, nas quais se abordamos a formação inicial docente na perspectiva da complexidade, por meio do desenvolvimento de atitudes reflexivas para a sedimentação dos conteúdos sob a forma de objeto de aprendizagem.

Segundo Belloni (2009), a Educação a Distância (EAD) é entendida como uma modalidade de educação que coaduna com o atual estágio da produção material da existência, pois as ferramentas interativas desenvolvidas nas décadas finais do século XX e no início do séc. XXI trouxeram consigo uma ampliação na capacidade comunicativa dos sujeitos, tanto espacial quanto temporalmente. Além disso, essas ferramentas são importantes repositórios de informações em ambientes virtuais.

A partir dessa breve contextualização, reflete-se sobre os aspectos que possibilitam pensar a inserção da formação em EAD na agenda das políticas públicas, como instrumento de inclusão social. Com efeito, "a disseminação da EAD on-line no Brasil muito deve, também, à boa receptividade e aos incentivos com que as autoridades públicas brasileiras acolheram as novas possibilidades de atuação educativa em larga escala" (BOHADANA; VALLE, 2009, p. 552). Tal argumento é adequado se pensarmos na extensão continental de nosso território e na concentração das Instituições de Ensino Superior (IES) nas metrópoles, o que deixa uma lacuna formativa no interior do território nacional.

A EAD, somada às novas tecnologias educativas, torna plausível a formação em nível superior de uma ampla e dispersa população, sem a necessidade de grandes aportes financeiros, se comparados aos exigidos pela estrutura tradicional de IES, uma vez que a EAD pode ser descentralizada entre as diferentes esferas do poder. $E$ essa modalidade de ensino tende a ser entendida como uma característica de eficiência. Logo, não foi somente no âmbito das políticas públicas que a EAD passou a ser vislumbrada. Segundo o censo realizado em 2012 pela Associação Brasileira de Educação a Distância (ABED), o mercado privado é o que representa o maior número de matrículas. 
A maioria das matrículas é de instituições privadas, sendo $60,5 \%$ em instituições com fins lucrativos e $14,5 \%$ em instituições sem fins lucrativos. As matrículas em instituições públicas correspondem a $15 \%$ do total, sendo $8 \%$ em instituições públicas federais e $7 \%$ em instituições públicas estaduais. As fundações educacionais possuem $2 \%$ das matrículas. Nos cursos promovidos pelas secretarias estaduais, as matrículas correspondem a $4 \%$ e, nas instituições do sistema "S", a 3\% (CENSO EAD, 2012, p. 20).

A EAD pode ser entendida como "uma modalidade de educação capaz de democratizar o acesso ao ensino superior" (MUGNOL, 2009, p. 335). O principal desafio da modalidade a distância "é o mesmo que enfrenta a educação presencial: elevar o nível de formação em distintos níveis, em especial no nível de formação universitária que está propiciando à população, bem como estimular a pesquisa com vista a avançar nessas melhorias" (MATIAS-PEREIRA, 2008, p. 46). No Brasil, a discussão sobre a construção de um modelo de Universidade Aberta ocorre na década de 1970, com a criação de um grupo de trabalho para a instituição da Universidade Aberta do Brasil (UAB).

[...] a partir dos tensionamentos políticos que constituíram a Nova República, foi possível observar as diferentes ações do Estado desencadeadas, por meio da iniciativa de um dos integrantes dos grupos de trabalho, constituído na década de 1970, em direção à propagada necessidade de se instituir uma 'política nacional de educação a distância' em direção também à proposição do projeto de iniciativa do Executivo, que dispunha sobre a criação da UAB. Tem-se ainda que a 'política nacional de educação a distância' é difundida como pré-requisito para a expansão da modalidade a distância e futura implantação de uma Universidade Aberta (LACÉ, 2014, p. 31).

Nesse sentido, a UAB no Brasil liga-se a uma discussão internacional baseada nas experiências de construção de modelos de Universidade Aberta. Em 1972 é fundada na Espanha a Universidad Nacional de Educación a Distancia (UNED), embora a UAB não reproduza o modelo desta experiência. Outra fonte de interação, mais próxima do modelo UAB, é encontrada na experiência Inglesa que em 1969 funda a Open University. Este modelo expandiu e consolidou-se na década de 1980 e na década de 1990 reformulou seu currículo e inovou nos métodos para aproveitar o potencial dos novos meios de ensino e aprendizagem com a exploração maciça da internet tornando-se pioneira no elearning no início da década de 2000.

Apesar das discussões acerca de um desenho político para a EAD, a implantação do modelo UAB só foi retomada no contexto da Reforma de Estado na década de 1990 e teve como resultado a abertura de uma consignação para a iniciativa privada, com a criação da Universidade Aberta autônoma, que consagra a implementação de um Sistema Nacional de Educação a Distância,

[...] durante os governos de Fernando Collor de Mello, Itamar Franco e os dois mandatos de Fernando Henrique Cardoso, onde foi possível analisar, por meio da reforma do Estado, como a 'política nacional de educação a distância', concretizada nos instrumentos legais, refletiram os pressupostos do neoliberalismo (LACÉ, 2014, p. 31).

Em 2005, a partir de um projeto-piloto do Banco do Brasil em parceria com o curso 
de Bacharelado em Administração Pública, "o Sistema UAB é apresentado e implementado como uma saída eficiente e com menor custo para a expansão do ensino superior e para a formação de professores" (LACÉ, 2014, p. 32), principalmente para dar conta das metas estabelecidas pelo Plano Nacional de Educação (PNE) e pela Lei de Diretrizes e Bases da Educação Nacional (LDBEN). "Neste movimento apressado, desnudou-se a ênfase no vínculo empresa-Estado, uma vez que a referida aliança tornou factível o Sistema UAB" (LACÉ, 2014, p. 32). Atualmente, a prioridade é oferecer formação inicial a professores em efetivo exercício na educação básica pública, com ou sem graduação. A UAB também pretende ofertar cursos a dirigentes, gestores e outros profissionais da educação básica da rede pública. Outro objetivo do programa é reduzir as desigualdades na oferta de ensino superior e desenvolver um amplo sistema nacional de educação superior a distância.

Outras experimentações na implementação de políticas públicas para a EAD foram surgindo no Rio de Janeiro, onde foi criado em 2000 um consórcio entre as universidades públicas. O projeto inicialmente pensado por Darcy Ribeiro (1922-1997) para criar a Universidade Aberta do Brasil remonta a 1993, quando foi idealizada e fundada a Universidade Estadual do Norte Fluminense Darcy Ribeiro (UENF). Seu primeiro reitor foi Wanderley de Souza, que, após a eleição de Anthony Garotinho para o Governo do Estado do Rio de Janeiro, em 1999, assumiu a Secretaria de estado e Ciência e Tecnologia e começou a implementar o sonho de Darcy Ribeiro. O primeiro passo foi um convite a Carlos Bielschowsky (UFRJ) para assumir a Superintendência da Secretaria de Ciência e Tecnologia, com a missão de articular as universidades para estabelecer um Projeto de EAD na área de Graduação (COSTA, 2005).

Entre os cursos criados estava o de Pedagogia para as séries iniciais, regido pela Universidade do Estado do Rio de Janeiro (UERJ) e pela Universidade Federal do Estado do Rio de Janeiro (UNIRIO). Em maio de 2002, a Assembleia Legislativa aprovou a criação da Fundação Centro de Ciências e Educação Superior a Distância do Estado do Rio de Janeiro (CECIERJ) - Consórcio CEDERJ. Atualmente, existem outros cursos de licenciatura: Ciências Biológicas, Física, Geografia, História, Letras (Português/Literatura), Matemática, Pedagogia, Química e Turismo. São ofertados ainda cursos de bacharelado em Administração, Administração Pública e Engenharia de Produção. É oferecida também a titulação em cursos de tecnólogo em Gestão e Turismo, Segurança Pública e Sistemas de Informação.

Segundo Costa (2005), o Consórcio tem como missão as vocações fundamentais: contribuir para fixar a população no interior; formar professores; desenvolver economicamente o Estado do Rio de Janeiro; contribuir com parâmetros de qualidade para cursos de graduação com o uso da metodologia da EAD. São três os elementos principais para alcançar essa meta, sendo que o caminho é desenhado na forma como os alunos estudam: "(1) Material didático de qualidade, impresso, em vídeo e no computador; (2) Interação permanente nos estudos; (3) Exames presenciais nos polos regionais" (COSTA, 2005, p. 8). Mas, para isso, encontram-se dois grandes desafios: "(1) oferecer um curso com a mesma qualidade dos cursos presenciais, (2) para alunos que moram no interior e, muitas vezes, têm uma formação deficiente" (COSTA, 2005, p. 7).

Em relação à formação deficiente, em 2001 foi criado e implementado pelo Instituto Paulo Montenegro e a Organização Não Governamental (ONG) Ação Educativa o Indicador de Alfabetismo Funcional (INAF), que é obtido por meio de entrevista e teste 
cognitivo aplicado a partir de amostra nacional de 2 mil pessoas entre 15 e 64 anos de idade, residentes em zonas urbanas e rurais de todas as regiões do país. O INAF avalia habilidades de leitura, escrita e matemática, classificando os respondentes em quatro níveis de alfabetismo: analfabetos, alfabetizados em nível rudimentar, alfabetizados em nível básico e alfabetizados em nível pleno. Os dois primeiros níveis são considerados como analfabetismo funcional. De acordo com o relatório:

\begin{abstract}
O Inaf completa uma série de 10 anos, na qual é possível perceber melhorias nos níveis de alfabetismo da população. Sem dúvida, tais melhorias correspondem à ampliação do acesso à escolarização, mas não na medida desejável. Os progressos localizam-se principalmente na transição do analfabetismo absoluto ou da alfabetização rudimentar para um nível básico de habilidades de leitura e matemática. Por outro lado, durante todo o período, mantém-se em torno de pouco mais de 1/4 da população a fração dos que atingem um nível pleno de habilidades, aquele que seria, em princípio, esperado ao completar os 9 anos do ensino fundamental (INSTITUTO PAULO MONTENEGRO, 2011, p. 8).
\end{abstract}

Bem, isso mostra que o desafio da formação inicial, presencial ou a distância, coloca-se antes de se chegar ao Ensino Superior. E mostra também que as políticas públicas para a formação inicial e continuada devem ser acompanhadas de outras políticas sociais que permitam ao discente superar a exclusão social uma vez que, "há uma correlação entre a renda familiar e o nível de alfabetismo, uma vez que a proporção de analfabetos e daqueles incluídos no nível rudimentar diminui sensivelmente à medida que aumenta a renda familiar" (INSTITUTO PAULO MONTENEGRO, 2011, p. 16).

A EAD, desenhada enquanto política pública, pode se tornar instrumento de inclusão social, seja por meio da formação inicial, seja por meio da formação continuada. Dado o caráter continental de nosso território e a concentração das Universidades nos grandes centros urbanos, a possibilidade que esta modalidade oferece é promissora. Com o relato da experiência que se faz no presente artigo, busca-se colaborar para o desenvolvimento de estratégias inovadoras no uso de tecnologias da informação e outros materiais, em um curso de formação inicial de professores no consórcio CEDERJ.

A Resolução CNE/CP No 1, de 18 de fevereiro de 2002, que institui Diretrizes Curriculares Nacionais para a Formação de Professores da Educação Básica em nível superior, curso de licenciatura e de graduação plena, estabelece em seu Art. $2^{\circ}$ e item VI o uso de tecnologias da informação e da comunicação e de metodologias, estratégias e materiais de apoio inovadores (BRASIL, 2002) ${ }^{1}$. A presente proposta busca demonstrar que é possível inovar com o que já se tem, com o simples, explorando-se a criatividade.

Considerar o professor um artesão é aceitar que ele não é um reprodutor, mas um reinventor de práticas, a partir das especificidades dos contextos nos quais atua, mobilizando elementos de que dispõe para fazer face a situações únicas, inesperadas e complexas (ALMEIDA, 2008, p. 17).

1 Alterada pela Resolução CNE/CP no2, de 09 de junho de 2015, que garante a formação complexa em instituições complexas. Esta regulação vem sendo substancialmente atacada pela nova composição do Ministério da Educação e Conselho Nacional de Educação (CNE), ao excluir de Fóruns Permanentes da sociedade civil - como a Associação Nacional de Formação dos Profissionais da Educação (ANFOPE) que auxiliaram ao organizar discussões em nível nacional para a redação do documento acerca da Base Nacional Curricular Comum (BNCC). 
Para que a transformação desejada se torne eficiente, é preciso que a implementação da inclusão seja uma realidade nas escolas. Isso requer também formação continuada, pois é usual haver professores sem formação complexa, ou seja, sem uma preparação para a constante reflexão sobre a prática, com foco na realidade do espaço educacional. A oficina pedagógica apresentada neste trabalho busca enquadrar a formação docente na perspectiva da complexidade por meio do desenvolvimento de atitudes reflexivas, garantidas enquanto objeto de aprendizagem.

\section{A oficina pedagógica em História na Educação 1 e 2}

As disciplinas História na Educação 1 e História na Educação 2 do curso de Pedagogia da UENF, no bojo do CEDERJ, objetivam, em linhas gerais, possibilitar aos alunos a reflexão sobre aspectos da disciplina escolar História, com ênfase nas abordagens e reflexões do contexto da Educação Infantil e das primeiras séries do Ensino Fundamental, contribuindo com a formação de educadores conscientes de seu papel educativo e de sua responsabilidade social. Entende-se que a compreensão de determinadas especificidades da natureza do conhecimento histórico é de suma importância para a formação de pedagogos.

Silva e Fonseca (2010) apontam para o papel educativo e formativo da História escolar, para a sua contribuição na formação da identidade e da cidadania, do respeito à diversidade cultural e do (re)conhecimento do outro, bem como na defesa da consolidação da democracia. Bittencourt (2015) nos faz lembrar que a legislação educacional e as propostas curriculares, em sua grande maioria, entendem que o ensino de História tem o propósito de contribuir para a formação de cidadãos críticos frente à sociedade em que estão inseridos. Tais finalidades não são novas, mas, atualmente, recebem considerável ênfase. A pesquisadora assevera que:

O ensino de História deve contribuir para libertar o indivíduo do tempo presente e da imobilidade diante dos acontecimentos, para que possa entender que cidadania não se constitui em direitos concedidos pelo poder instituído, mas tem sido obtida em lutas constantes e em suas diversas dimensões (BITTENCOURT, 2015, p. 20).

A reflexão histórica escolar possibilita que o estudante:

[...] pratique um exercício de reflexão que o encaminhará para outras reflexões, de natureza semelhante, em sua vida e não necessariamente só na escola; pois a história produz um conhecimento que nenhuma outra disciplina produz - e ele nos parece fundamental para a vida do homem, indivíduo eminentemente histórico (CABRINI, 2000, p. 36).

O ensino de História pode propiciar a formação de sujeitos históricos: os jovens podem se perceber enquanto indivíduos situados em um dado espaço e tempo e identificar outras realidades em lugares e tempos distintos do seu, perceber as transformações históricas, enfim, podem se identificar enquanto agentes históricos 
capazes de intervir e atuar nas decisões coletivas, no âmbito em que vivem. Eles também fazem história. Acredita-se que todas essas características do ensino de História devem fazer parte do objeto de discussão do curso de formação de pedagogos, já que de alguma forma eles poderão ter contato com essa disciplina em suas práticas futuras. Outrossim, certos aspectos referentes à História enquanto ciência também possuem sua relevância e são trazidos aos alunos do curso de Pedagogia.

Concorda-se com Maria Belloni, ao apontar que:

Pedagogia e tecnologia (entendidas como processos sociais) sempre andaram de mãos dadas: o processo de socialização das novas gerações inclui necessária e logicamente a preparação dos jovens indivíduos para o uso dos meios técnicos disponíveis na sociedade, seja o arado seja o computador (BELLONI, 2002, p. 118).

Essa reflexão leva ao pensamento sobre o material humano que se forma nos cursos de Pedagogia a distância e as estratégias de ensino e aprendizagem que são adotadas pelos docentes/tutores, visando alcançar o objetivo de preparar os discentes para o uso dos meios técnicos disponíveis.

Diante disso, nesta seção, apresenta-se o relato de experiência de aplicação da oficina pedagógica, que representou um novo meio de avaliar os discentes do $5^{\circ}$ e $6^{\circ}$ período do curso de Pedagogia do CEDERJ da UENF, na Avaliação a Distância (AD) de História na Educação 1 e 2. Primeiramente, será exposta a organização da atividade nas respectivas disciplinas e, em seguida, serão descritos a preparação do material apresentado pelos alunos e o uso dos meios digitais, entre outros materiais. Por fim, será feita uma breve reflexão acerca da participação dos alunos nas atividades do curso, com foco na oficina pedagógica.

Segundo Paviani e Fontana (2009), a oficina pedagógica é caracterizada pela integração entre teoria e prática, é uma forma de construir conhecimento tendo como base a ação e a reflexão. Para as referidas autoras, a oficina pedagógica busca atender às seguintes finalidades: "(a) articulação de conceitos, pressupostos e noções com ações concretas, vivenciadas pelo participante ou aprendiz; e (b) vivência e execução de tarefas em equipe, isto é, apropriação ou construção coletiva de saberes" (PAVIANI; FONTANA, 2009, p. 78). Conforme Anastasiou e Alves (2009, p. 96), a Oficina "é lugar de pensar, descobrir, reinventar, criar e recriar, favorecido pela forma horizontal na qual a relação humana se dá". Assim, foi possível constatar que a oficina pedagógica propiciada pelas disciplinas de História na Educação 1 e 2 muito contribuiu para a articulação profícua entre teoria e prática, na medida em que grupos de alunos puderam executar as suas reflexões e o que aprenderam em ambos os componentes curriculares através de elaboração de materiais e apresentações criativas.

A organização e a estruturação da oficina pedagógica ficou a cargo dos professores coordenadores, das tutoras a distância e do tutor presencial das disciplinas de História na Educação 1 e 2, nos polos da Pedagogia CEDERJ-UENF, a saber: Bom Jesus do Itabapoana, Itaperuna, São Fidélis e São Francisco de Itabapoana. Cabe esclarecer que os tutores presenciais são aqueles que orientam e atendem os alunos nos polos, aqueles que possuem contato direto com os estudantes. Já os tutores a distância: 
http://periodicos.letras.ufmg.br/index.php/textolivre

Belo Horizonte, v. 11, n. 3, p. 176-191, set.-dez. 2018 - ISSN 1983-3652 DOI : $10.17851 / 1983-3652 \cdot 11 \cdot 3 \cdot 176-191$

têm como base para seu trabalho a instituição de ensino, a partir da qual realiza mediação do processo pedagógico junto a estudantes geograficamente distantes, referenciados aos polos de apoio presencial. Sua principal atribuição é o esclarecimento de dúvidas de conteúdo do material didático e ajuda de caráter geral ao estudante, através do telefone, de fóruns de discussão pela Internet, de participação em videoconferências, e outras tarefas, de acordo com a disponibilidade tecnológica e o projeto pedagógico (COSTA, 2007, p. 11).

Em História na Educação 1, a oficina pedagógica ocorreu em duas etapas. $\mathrm{Na}$ primeira fase, tendo por base as discussões suscitadas pelos textos apresentados nessa disciplina, os alunos organizados em grupos de quatro deveriam elaborar o planejamento de uma aula, escolhendo uma das seguintes indicações na elaboração do plano: 1) o trabalho com as noções de tempo; 2) o trabalho com o(s) conceito(s) de História; 3) o trabalho com documentos textuais/escritos nas aulas de História; 4) o trabalho com a pesquisa na sala de aula de História; 5) o trabalho com documentos orais e/ou imagens históricas nas aulas de História. O foco de cada indicação era o Ensino Fundamental 1.

Essa atividade compôs a Avaliação a Distância 1 (AD1), que teve um total de 10 pontos. Os estudantes deveriam montar os grupos e elaborar o planejamento. Um modelo de plano foi disponibilizado aos discentes para que pudessem construir o trabalho. Após a concretização dessa avaliação, um integrante do grupo deveria postar o trabalho em uma sala de aula específica da disciplina, disponível na plataforma Moodle do CEDERJ. No período de construção da AD1, os alunos poderiam tirar suas dúvidas através da sala de tutoria da plataforma ou do atendimento por telefone, na sala de tutoria do CEDERJ na UENF.

De forma geral, a maioria dos alunos realizou a avaliação: alguns efetivaram o planejamento sozinhos e em grupo, conforme o indicado. Todos os planos foram considerados para correção, pois se entende que os alunos que cursam uma graduação a distância podem apresentar dificuldades em manter contato com os seus colegas de turma. Sobre os trabalhos, verificou-se a oscilação entre propostas de ótima qualidade e outras não tão boas assim. Infelizmente, os plágios ainda persistem e esse é um ponto que precisa ser constantemente lembrado: trabalhos meramente copiados e sem as devidas referências não podem ser permitidos. Este é um grande desafio colocado aos alunos na construção do conhecimento.

No tocante à segunda etapa da oficina pedagógica de História na Educação 1, os discentes deveriam, a partir do planejamento de uma aula que foi preparado para AD1, organizar uma exposição simulando como fariam para desenvolver o referido plano nas aulas de História. Junto com a apresentação, os estudantes também deveriam elaborar algum material para exposição, que estivesse relacionado com o que pretendiam apresentar. Essa atividade representou a Avaliação a Distância 2 (AD2) e foi avaliada no total de 10 pontos. Os trabalhos deveriam ser apresentados pelos alunos nos polos aos quais pertenciam e pelos mesmos grupos da AD1, ou individualmente para quem não havia realizado a AD1 em equipe.

Para a preparação da exposição nos polos, os grupos recorreram à tutoria com o intuito de sanar suas dúvidas em relação ao plano de aula que foi construído na AD1 e que deveria ser apresentado na AD2. Os estudantes tomaram conhecimento dos erros ou incongruências que cometeram no planejamento e tiveram a oportunidade de refazer ou aprimorar esse trabalho, para que pudessem apresentar um plano com melhor qualidade 
e coesão. As equipes que não tiveram um desempenho muito bom na AD1 alcançaram uma evolução significativa na AD2.

$\mathrm{O}$ processo de ensino e aprendizagem realizado mediante os esclarecimentos e questões postas pela tutora através da sala de tutoria da plataforma CEDERJ, a partir de um plano concluído pelos estudantes, muito contribuiu para que esses discentes refletissem melhor sobre como construir um plano de aula com propostas que fizessem sentido. Os discentes puderam, assim, pensar em uma aula de História que fosse coerente e relevante para os alunos dos anos iniciais do Ensino Fundamental, utilizando diferentes tecnologias e outros materiais.

Por exemplo, muitos discentes matriculados na disciplina de História na Educação 1 propuseram o trabalho com imagens históricas em sala de aula. Porém, alguns desses estudantes, ao elaborarem o plano, apresentaram tais imagens como se fossem a verdade sobre um dado fato histórico, como se fossem a realidade incontestável. Assim, foi sendo trabalhada com os alunos a assertiva de que as imagens não apresentam a realidade tal como ela é ou como ela foi, mas são recriações da realidade, representações do real. Essa questão faz toda a diferença no processo de ensino e aprendizagem no âmbito da Educação Básica. Nesse sentido, concorda-se com Vergara (2007, p. 6) quando afirma que "o papel do tutor é de extrema relevância nesse processo. A presteza nas respostas ao aluno é fundamental, já que não existe o contato presencial, o 'olho no olho"'.

É oportuno mencionar que, de modo geral, além da sala de tutoria da plataforma CEDERJ, os meios de ensino e aprendizagem de disciplinas também se dão através de fóruns, blog, e-mail, telefone e outros mecanismos.

No que diz respeito à disciplina de História na Educação 2 (ofertada para o $6^{\circ}$ período da Graduação em Pedagogia), o momento de aprendizado foi igualmente profícuo, proporcionando aos alunos um ambiente presencial de troca de saberes, além das provas - o único mecanismo de avaliação - e tutorias presenciais do CEDERJ UENF $^{2}$. Na proposta avaliativa, denominada de oficina pedagógica, os discentes, em grupos de quatro a cinco integrantes, elaborariam um projeto que envolvesse: alguma das temáticas estudadas anteriormente nas aulas on-line, disponíveis na plataforma; os Parâmetros Curriculares Nacionais (PCN); e a interdisciplinaridade, envolvendo outras disciplinas escolares na execução do projeto. Diferentemente da História na Educação 1 , não houve uma obrigatoriedade de envio do material para a plataforma, pois o intuito era que os alunos construíssem suas ideias e procurassem auxílio conforme as necessidades fossem surgindo.

Assim, no dia 7 de outubro do ano de 2017, os estudantes matriculados em História na Educação 1 e 2, divididos em diferentes grupos, compareceram aos seus respectivos polos para apresentarem a Oficina. Os educadores (tutores e professora) se organizaram entre si e cada um compareceu a um polo para avaliar as exposições. Entende-se que o processo de realização e apresentação da oficina pedagógica das disciplinas citadas anteriormente foi, de modo geral, bastante proveitoso tanto para os alunos como para os docentes e tutores. Antes da iniciativa da oficina pedagógica, as atividades realizadas pelos discentes (AD) eram postadas e avaliadas na própria plataforma do CEDERJ, sem

2 O curso de Pedagogia do CEDERJ-UENF conta com as formas de tutoria presencial e a distância, no entanto a primeira modalidade só ocorre nas disciplinas até o $4^{\circ}$ período, sendo assim, as disciplinas aqui referidas, ofertadas no $5^{\circ}$ e $6^{\circ}$ período, não possuem esse suporte. 
o contato direto com os estudantes e sem o manuseio e a exploração de outras tecnologias. Enquanto primeira experiência, que inaugurou uma nova forma de ensino e aprendizagem, de avaliação e de execução de atividades, os sujeitos envolvidos avaliaram a Oficina de forma muito positiva.

\subsection{A participação efetiva na atividade: uma análise da oficina pedagógica}

A partir das experiências adquiridas com a proposta da oficina pedagógica, constatou-se que tal atividade contribuiu significativamente para uma maior aproximação entre professores, tutores e estudantes. Vergara (2007, p. 1-2) aponta que o relacionamento entre docente e aluno, facilmente percebido no ensino presencial, é visto no âmbito da Educação a Distância como algo limitado, o que pode minimizar a importância da EAD. Todavia, como aponta a pesquisadora, o relacionamento entre docente e estudante "também existe na EAD, embora de forma diferenciada e, tal como a educação presencial, expande-se para outras pessoas que, no caso da EAD, compõem as equipes acadêmicas, de produção, de operação e até a comercial, essa última quando existe". Com a proposta da oficina pedagógica, procuramos de alguma forma estreitar ainda mais os laços com os nossos alunos, conhecê-los melhor e saber mais sobre o que eles têm a dizer. Além disso, percebemos que a Oficina também nos possibilitou uma aproximação dos funcionários que trabalham nos polos, na medida em que organizávamos os trâmites para a realização das atividades naqueles locais e com a nossa presença no dia das apresentações.

De maneira geral, constatou-se que a grande maioria dos trabalhos apresentados foi de boa qualidade. Teve-se a oportunidade de verificar uma multiplicidade de formas de apresentação e de materiais exibidos pelos estudantes, com o uso de diferentes tecnologias. Os grupos de alunos utilizaram diferentes recursos e instrumentos para expor as suas atividades e apresentar os seus trabalhos, tais como datashow, aparelho de som, maquetes, materiais recicláveis, painéis, cartazes, vídeos e dinâmicas. Pelos limites do presente texto, destacam-se brevemente nas linhas que se seguem alguns aspectos dos trabalhos e objetos desenvolvidos pelos discentes que mais nos chamaram atenção.

No polo de São Fidélis, um grupo de estudantes matriculados na disciplina História na Educação 1 e outro grupo que cursa História na Educação 2 abordaram o mesmo tema, tocando em questões que envolvem os brinquedos e brincadeiras, estabelecendo ligações entre o ato de brincar no passado e no presente e trazendo, assim, discussões que demonstraram como o ensino e aprendizagem em História podem estar articulado a outras disciplinas, como Artes. Ambos os grupos produziram um material rico e de muito boa qualidade. Utilizando objetos recicláveis como litros, tampas, latas, potes, sacos de papel e barbantes, os discentes produziram vários brinquedos comumente usados no passado, tais como peteca, vai e vem, pé de lata, carrinhos, entre outros. Essa proposta elaborada pelos alunos do CEDERJ pode ser uma boa forma de ensinar História de forma lúdica. Outras apresentações foram relacionadas à história da cidade, tema muito importante para o estudo de História nas séries iniciais, visto que partimos do local para o geral. Foram trabalhadas ainda informações riquíssimas sobre a sociedade indígena que habitou aquela região, buscando explorar a relação da cultura indígena com a local.

Ainda no referido polo, grupos de estudantes exploraram os recursos do datashow 
e do aparelho de som para apresentar as suas propostas. No datashow, por exemplo, foi apresentado um pequeno vídeo de animação que poderia ser trabalhado com as crianças nas aulas de História. Já no aparelho de som foi reproduzida uma música sobre a escravidão e sua abolição no Brasil, que poderia ser discutida e analisada com os alunos da Educação Infantil.

No polo de Bom Jesus do Itabapoana, a proposta de uma aula planejada por um grupo de discentes do curso de Pedagogia e que seria ministrada para as crianças dos anos iniciais do Fundamental tocou na história da cidade de São José do Calçado, localizada no estado do Espírito Santo e situada nas proximidades do referido polo. O grupo abordou aspectos da economia, da educação e da cultura local e oportunizou a degustação de alguns alimentos típicos ou muito consumidos na cidade, tais como o café, a bananada calçadense, doces, frutas e a broinha de fubá, muito conhecida na região, que fez com que seus moradores apelidassem o município de "Terra da Broinha".

Já no polo de São Francisco do Itabapoana, um grupo de professoras apresentou um trabalho muito interessante acerca da História da África, com enfoque no preconceito e na escravidão. O que chamou a atenção foi o fato de que todos os grupos desse polo, no âmbito da disciplina História na Educação 2, realizaram a oficina pedagógica versando sobre o tema supracitado. As equipes de História na Educação 1 também concretizaram boas apresentações sobre dos meios de transporte no passado e no presente, a chegada da família real portuguesa ao Brasil e o tempo histórico, utilizando-se de múltiplos recursos, tais como imagens, cartazes e um carrinho de brinquedo confeccionado de materiais recicláveis.

Por fim, no polo de Itaperuna, teve-se igualmente a oportunidade de presenciar trabalhos de elevada qualidade, que utilizaram recursos como datashow, cartazes, cenas de filmes, imagens, objetos antigos, maquetes e outros. As equipes apresentaram propostas significativas de temas distintos que poderiam ser ministrados aos alunos das séries iniciais. Chamou-nos a atenção uma maquete muito bem-elaborada, que representava uma caverna do filme "Os Croods", feita por uma equipe que almejava abordar a pré-história. Outra apresentação tratou da questão da estrutura familiar, enfocando as mudanças em sua organização e no papel feminino na sociedade, ou seja, como as mulheres ao longo do tempo foram ganhando espaço no mercado de trabalho. É uma maneira interessante de entender que todos possuem história, dado que, novamente, observa-se a ênfase do particular para o geral.

$\mathrm{Na}$ educação a distância, a preparação de um material/aula é muito importante para o desenvolvimento das atividades, pois certas vezes os alunos aprendem por conta própria e não podem contar com o apoio de um professor presencial. Por isso, todas as atividades são pensadas para despertar o máximo de interesse nos alunos, contribuindo, assim, para o desenvolvimento do processo de ensino e aprendizagem. Na visão de Costa (2007):

É necessário que o material didático seja estruturado em linguagem dialógica, utilize um conjunto de mídias compatíveis e coerentes com o contexto socioeconômico do público-alvo, com o objetivo de promover autonomia do aluno, desenvolver sua capacidade para aprender e controlar o próprio desenvolvimento (COSTA, 2007, p. 11). 
Nesse caminho é importante destacar que, mesmo com toda essa preparação do material, focada sempre no maior aproveitamento do discente, ainda se encontram dificuldades para obter uma participação ativa nas atividades desenvolvidas no curso a distância, tanto on-line como nas provas presenciais, mesmo nas atividades avaliativas. Sendo assim, percebe-se que "diferentes contextos de estudo do aluno passam a afetar a participação e o rendimento em cursos a distância" (ABBAD et al., 2010, p. 294).

Costa (2007, p. 10) indica que, "neste quadro, as reais condições do cotidiano e necessidades dos alunos são fatores determinantes para o desenho pedagógico dos cursos, para a organização curricular e na seleção dos recursos tecnológicos a serem utilizados".

Pode-se ressaltar também que as inúmeras atividades diárias dos participantes do curso, como trabalho e cuidado da família, visto que as matrículas são majoritariamente femininas $(88,79 \%)^{3}$, concorrem para a não participação nas avaliações e em outros exercícios não pontuados, como as atividades do caderno didático ${ }^{4}$.

$\mathrm{Na}$ educação a distância, os espaços e papéis dos alunos, tutores e professores estão bem definidos em virtude das diferentes funções e tarefas de atuação/participação. Nesse sentido, torna-se necessária a "mediação do processo pedagógico, que pode ganhar em qualidade se realizada por uma equipe constituída de tutores presenciais e [...] a distância. Esta mediação deve explorar tecnologias de informação e comunicação acessíveis aos estudantes" (COSTA, 2007, p. 10). Segundo Belloni (2002), as tecnologias de comunicação podem ser exploradas por meio da mediatização técnica ${ }^{5}$, tanto em encontros presenciais, de discussão entre alunos e tutores, como a distância, buscando aprimorar as atividades desenvolvidas on-line. A autora ainda complementa ao sublinhar que "o próprio conceito de distância está se transformando, como as relações de espaço e tempo, em virtude das incríveis possibilidades de comunicação a distância que as tecnologias de telecomunicações oferecem" (BELLONI, 2002, p. 123).

Todas essas considerações são importantes e justificam mais uma vez a escolha de uma atividade presencial na avaliação a distância (AD), em que se busca uma maior participação de todos e interação com as/os tutoras/es e coordenadores/as da disciplina. Além disso, com a Oficina, procurou-se oportunizar um espaço para que os próprios estudantes do curso de Pedagogia pudessem explorar distintas formas de ensino, entre elas, o uso de diferentes tecnologias nas aulas de História com alunos da Educação Infantil.

Pode-se perceber que a oficina pedagógica manteve o padrão de adesão dos discentes, como se observa no Gráfico 1, ficando apenas o Polo de São Francisco de Itabapoana (SFR) abaixo da média, com a participação e não participação equilibradas em $50 \%$.

3 Na disciplina História na Educação 1, de 100 alunos, apenas 8\% são homens (8). Em História na Educação 2, de 114 alunos, apenas 14\% são do sexo masculino (16).

4 Nas disciplinas em questão, os alunos que não participam das atividades correspondem à minoria $(\approx$ $30 \%$ a $40 \%)$.

5 "[...] a concepção, a fabricação e o uso pedagógico de materiais multimídia gera novos desafios para os atores envolvidos nestes processos de criação (professores, realizadores, informatas etc.)" (BELLONI, 2002, p. 123). 
Gráfico 1: Participantes da oficina pedagógica de história na educação 1 e 2, por polos.

\section{Bom Jesus do Itabapoana}

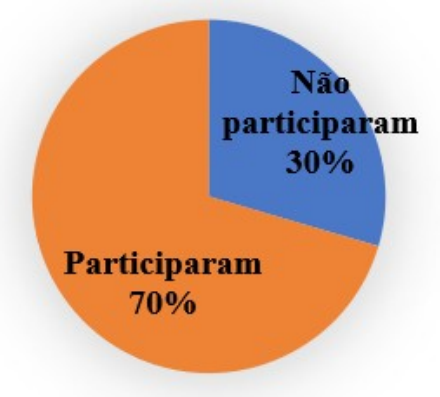

Itaperuna

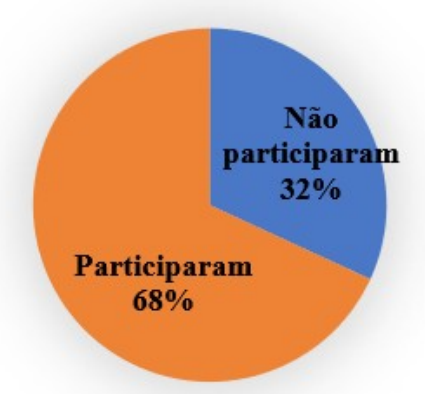

São Francisco de Itabapoana

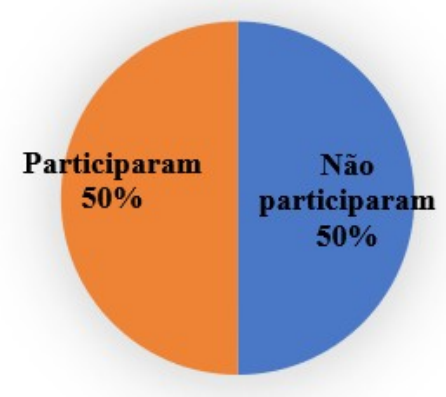

São Fidélis

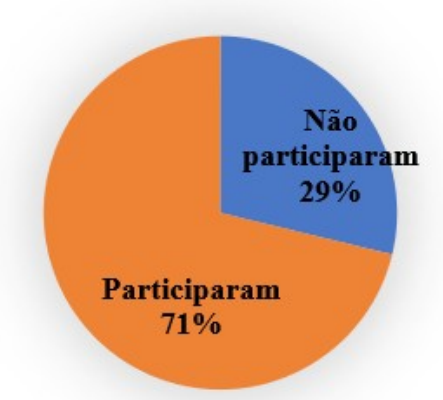

Fonte: elaboração dos autores com base nas listas de presença da oficina pedagógica.

Em síntese, pode-se considerar positiva a participação nesta atividade, visto que muitos alunos compareceram à etapa presencial e conseguiram articular as mídias digitais aos conceitos históricos de maneira bem-sucedida. Na etapa virtual, os alunos de História 1 enviaram antecipadamente a proposta do plano de aula, conforme indicado anteriormente, e que serviu como nota para a AD1. Assim, os participantes receberam um feedback dos planos enviados, com indicações para aperfeiçoarem as estratégias das aulas. Nota-se que foi uma etapa importante, visto que já se percebia uma adesão dos discentes e, nas apresentações, foi possível identificar que muitos buscaram incorporar as considerações aos planos, apresentando um trabalho mais concreto e linear.

Já em História 2, propôs-se como atividade na AD1 o uso de estratégias pedagógicas, visando minimizar o papel secundário do ensino de História nas séries iniciais. Sendo assim, essas estratégias puderam enriquecer os projetos da AD2, servindo de subsídios para as propostas dos discentes. Os contatos entre a tutora e os discentes foram bastante autônomos, deixando a cargo destes últimos o envio de dúvidas e questionamentos. Esse fator apresentou pontos positivos, porque os discentes puderam explorar ao máximo todos os recursos disponíveis na plataforma, como vídeos, links para websites históricos, artigos e outros; e apresentou também pontos negativos, pois muitos grupos utilizaram a mesma temática, trazendo temas muito amplos e, em alguns casos, incongruentes com o nível de escolaridade para o qual deveriam aplicá-los.

Essas considerações nos indicam que é necessário um acompanhamento mais direcionado, como ocorreu em História 1, de modo a ajudar os estudantes a construir um projeto que seja adequado mais ao nível de ensino priorizado, em que o lúdico possa 
estar presente. Outro fator que merece destaque é que muitos participantes já se encontram em sala de aula, buscando no curso de Pedagogia uma ampliação da qualificação e do aprendizado. Essa questão também sinaliza para a necessidade de um trabalho mais focalizado, pois nota-se que alguns conceitos precisam ser mais discutidos, problematizados e desconstruídos, buscando-se mostrar aos discentes que "ensinar história nas séries iniciais [...] é tornar a sala de aula um lugar privilegiado de investigação, de reflexão e de produção do conhecimento" (MENEZES; SILVA, 2007, p. 226).

\section{Considerações finais}

A oficina pedagógica representou uma experiência ímpar e prazerosa. Não apenas os alunos aprenderam com as atividades, mas também os tutores/as e professores/as tiveram a oportunidade de adquirir novos saberes, entre eles, os múltiplos usos de diferentes materiais e tecnologias que podem ser empregadas no ensino de História. Além disso, no polo de Bom Jesus, por exemplo, a partir das apresentações dos alunos, o tutor tomou conhecimento de questões da cultura local e do patrimônio material e imaterial em regiões adjacentes ao polo, que até então não conhecia.

Em São Fidélis não foi diferente: informações riquíssimas sobre a sociedade indígena que habitou aquela região, bem como conhecimentos sobre a atuação dos descendentes daquele povo nos dias de hoje também foram proveitosos para a tutora que realizou as avaliações no referido polo.

Também em São Francisco de Itabapoana um dos grupos apresentou informações organizadas sobre uma comunidade Quilombola do município, desconhecida para outros discentes e para a docente.

Assim, entende-se que o estudante aprende com o docente e vice-versa. 0 educador não é o único detentor do conhecimento; os discentes também possuem a sua bagagem e podem contribuir na construção de diferentes saberes.

A experiência oportunizou também um momento de discussão e desconstrução de estereótipos sobre alguns grupos, buscando abandonar o discurso do senso comum. Por exemplo, as sociedades indígenas e africanas, especificamente os casos da colonização e escravidão no Brasil, apareceram recorrentemente nas apresentações sob a ótica da folclorização, sem a percepção de processos mais importantes como as lutas e resistências destes povos, percepção esta que foi problematizada ao longo da atividade.

\section{Referências}

ABBAD, G. da S.; ZERBINI, T.; SOUZA, D. B. L. de. Panorama das pesquisas em educação a distância no Brasil. Estudos de Psicologia, v. 15, n. 3, set.-dez./2010, 291298. Disponível em: <http://www.scielo.br/pdf/epsic/v15n3/a09v15n3>. Acesso em: 26 jun. 2017.

ALMEIDA, L. R. Diretrizes para a formação de professores: uma abordagem possível. In: 
PLACCO, V. M. N. de S.; ALMEIDA, L. R. (Org.). O coordenador pedagógico e os desafios da educação. São Paulo: Edições Loyola, 2008. p. 9-23.

ANASTASIOU, L. das G. C.; ALVES, L. P. Processos de Ensinagem na Universidade: pressupostos para as estratégias de trabalho em aula. $5^{\mathrm{a}}$ ed. Joinville: Univille, 2009.

BELLONI, M. L. Educação a distância. 5ª ed. Campinas: Autores Associados, 2009.

BELLONI, M. L. Ensaio sobre a Educação a Distância no Brasil. Educação \& Sociedade, Campinas-SP, ano XXIII, n. 78, abr. 2002. Disponível em: <http://www.scielo.br/pdf/es/v23n78/a08v2378>. Acesso em: 26 jun. 2018.

BITTENCOURT, C. Capitalismo e Cidadania nas atuais propostas curriculares de História. In: BITTENCOURT, Circe (Org.). O saber histórico na sala de aula. 12.ed. São Paulo: Contexto, 2015. p. 11-27.

BOHADANA, E.; VALLE, L. do. O quem da Educação à distância. Revista Brasileira de Educação, Rio de Janeiro, v. 14, n. 42, p. 551-564, 2009. Disponível em <http://www.scielo.br/pdf/rbedu/v14n42/v14n42a11.pdf>. Acesso em: 26 jun. 2018.

BRASIL. RESOLUÇÃO CNE/CP 1, DE 18 DE FEVEREIRO DE 2002. Institui Diretrizes Curriculares Nacionais para a Formação de Professores da Educação Básica, em nível superior, curso de licenciatura, de graduação plena. Disponível em: <http://portal.mec.gov.br/cne/arquivos/pdf/rcp01_02.pdf>. Acesso em: 26 jun. 2018.

CABRINI, C. O que achamos importante lembrar sobre o ensino de história ou fundamentação teórica da proposta. In: CABRINI, C. et. al. Ensino de História, revisão urgente. São Paulo: EDUC, 2000. p. 31-44.

CENSO EAD. BR. Relatório analítico da aprendizagem a distância no Brasil 2011. São Paulo: Pearson Education do Brasil, 2012 (Relatório).

COSTA, C. J. Licenciaturas a distância: a experiência do CEDERJ. 2005. Disponível em: $<$ http://www.cinted.ufrgs.br/ciclo5/apresentacoes/CEDERJ/apres_cederj_ufrgs_junh2005.p df>. Acesso em: 26 jun. 2018.

COSTA, C. J. Modelos de Educação Superior a Distância e Implementação da Universidade Aberta do Brasil. Revista Brasileira de Informática na Educação, Porto Alegre-RS, v. 15, n. 2, p. 9-16, mai.-ago. 2007. Disponível em: <http://www.brie.org/pub/index.php/rbie/article/view/63/53>. Acesso em: 26 jun. 2018.

INSTITUTO PAULO MONTENEGRO. Inaf 2011 mostra evolução da educação no Brasil. Disponível em: <https://drive.google.com/open? id=0B5WoZxXFQTCRWE5UY2FiMzFhZEk>. Acesso em: 26 jun. 2018.

LACÉ, A. M. A Universidade Aberta do Brasil (UAB): das origens na ditadura militar ao século XXI. 2014. 313 f., il. Tese (Doutorado em Educação) - Universidade de Brasília, 
Brasília, 2014.

MATIAS-PEREIRA, J. Políticas públicas de educação no Brasil: a utilização da ead como instrumento de inclusão social. Journal of Technology Management \& Innovation, v. 3 n. 2, p. 44-55, 2008. Disponível em: <http://www.jotmi.org/index.php/GT/article/view/art79/544>. Acesso em: 26 jun. 2018.

MENEZES, L. M. de; SILVA, M. F. de S. Ensinando história nas séries iniciais: alfabetizando o olhar. In: MONTEIRO, A. M.; GASPARELLO, A. M.; MAGALHÃES, M. de S. (Org.). Ensino de História: sujeitos, saberes e práticas. Rio de Janeiro: Mauad X: FAPERJ, 2007. p. 215-228.

MUGNOL, M. A educação a distância no Brasil: conceitos e fundamentos. Revista Diálogo Educação, v. 9, n. 27, p. 335-349, 2009. Disponível em: $<$ http://www2.pucpr.br/reol/index.php/DIALOGO?dd1=2738\&dd99=pdf>. Acesso em: 26 jun. 2018.

PAVIANI, N. M. S.; FONTANA, N. M. Oficinas Pedagógicas: relato de uma experiência. Conjectura, v. 14, n. 2, p. 77-88, 2009. Disponível em: <http://www.ucs.br/etc/revistas/index.php/conjectura/article/view/16/15>. Acesso em: 26 jun. 2018.

SILVA, M. A. da.; FONSECA, S. G. Ensino de História Hoje: errâncias, conquistas e perdas. Revista Brasileira de História, São Paulo, v. 31, p. 13-33, 2010.

VERGARA, S. C. Estreitando relacionamentos na educação a distância. Cadernos EBAPE.BR, volume $\mathrm{V}$, edição especial, p. 1-8, jan. 2007. Disponível em: <http://bibliotecadigital.fgv.br/ojs/index.php/cadernosebape/article/view/5427/4161>. Acesso em: 26 jun. 2018.

Recebido em dia 06 de março de 2018. Aprovado em dia 16 de julho de 2018. 